\section{Taxonomic Note}

\author{
Correspondence \\ Stephen K. Farrand \\ stephenf@uiuc.edu
}

\section{Agrobacterium is a definable genus of the family Rhizobiaceae}

\author{
Stephen K. Farrand, ${ }^{1}$ Peter B. van Berkum ${ }^{2}$ and Philippe Oger ${ }^{3}$
}

\author{
${ }^{1}$ Departments of Crop Sciences and Microbiology, University of Illinois at Urbana-Champaign, \\ 240 ERML, 1201 West Gregory Drive, Urbana, IL 61801, USA \\ ${ }^{2}$ Soybean Genomics and Improvement Laboratory, Plant Sciences Institute, USDA-ARS, \\ Beltsville, MD, 20705, USA \\ ${ }^{3}$ Laboratoire de Sciences de la Terre, Ecole Normale Superieure de Lyon, \\ 69364 Lyon Cedex 07, France
}

\begin{abstract}
Members of the genus Agrobacterium constitute a diverse group of organisms, all of which, when harbouring the appropriate plasmids, are capable of causing neoplastic growths on susceptible host plants. The agrobacteria, which are members of the family Rhizobiaceae, can be differentiated into at least three biovars, corresponding to species divisions based on differential biochemical and physiological tests. Recently, Young et al. [Int J Syst Evol Microbio/ 51 (2003), 89-103] proposed to incorporate all members of the genus Agrobacterium into the genus Rhizobium. We present evidence from classical and molecular comparisons that supports the conclusion that the biovar 1 and biovar 3 agrobacteria are sufficiently different from members of the genus Rhizobium to warrant retention of the genus Agrobacterium. The biovar 2 agrobacteria cluster more closely to the genus Rhizobium, but some studies suggest that these isolates differ from species of Rhizobium with respect to their capacity to interact with plants. We conclude that there is little scientific support for the proposal to group the agrobacteria into the genus Rhizobium and consequently recommend retention of the genus Agrobacterium.
\end{abstract}

In their recent paper, Young et al. (2001) addressed the difficult and controversial question of the taxonomy of two genera, Agrobacterium and Allorhizobium, within the family Rhizobiaceae. Over the past three decades this has become a recurrent issue and arises in part from the differentiation of the genus Agrobacterium from the genus Rhizobium as the group of nitrogen non-fixing species of rhizobia that produce 'other types of hypertrophies' (Jordan, 1984). It is clear from a current understanding of a large body of descriptive work that species within the genus Agrobacterium do not form a monophyletic group. This conclusion is not restricted to Agrobacterium; it also applies to other genera in the family Rhizobiaceae, and led recently to the division of the genus Rhizobium into several genera including Rhizobium, Mesorhizobium and Sinorhizobium. Proposals on how to resolve the issue of Agrobacterium taxonomy have appeared from time to time, but they have had little impact on how the members of this genus are described and named in the scientific literature. In their paper, Young et al. (2001) explore the history of this taxonomic issue and concluded by proposing that all

Published online ahead of print on 13 December 2002 as DOI 10.1099/ijs.0.02445-0.

Abbreviation: RIME, rhizobium-specific intergenic mosaic element. members of the genera Agrobacterium and Allorhizobium be included in the genus Rhizobium. While we appreciate the efforts of Young et al. (2001), in this letter we explain why we cannot lend our support to their proposal.

There is no doubt that the genus Agrobacterium is polyphyletic. There also is no doubt that the agrobacteria and the rhizobia constitute a paradoxically diverse group of related members of the $\alpha$-Proteobacteria. Based on biochemical and phenotypic analyses, Keane et al. (1970) suggested that the genus Agrobacterium be subdivided into two biovars. Subsequently, a third group, biovar 3, was described and includes isolates from grapevine (Kerr \& Panagopoulos, 1977). It is remarkable how accurate and useful this set of divisions is, and for the purposes of this discussion we will use these biovar designations for the three major groupings of the genus Agrobacterium, precluding the need for species names. More recently, $16 \mathrm{~S}$ rRNA sequence analysis supports, in our opinion, this subdivision. The biovar 1 isolates all group together, and cluster with Allorhizobium undicola and several atypical Rhizobium species, including Rhizobium galegae and Rhizobium huautlense. Significantly, this group correlates well with the Agrobacterium tumefaciens group of Holmes \& Roberts (1981), defined by numerical taxonomy, and also with the divisions proposed by Tighe et al. (2000), based on analysis 
of fatty acid profiles. 16S rRNA analyses place isolates of Agrobacterium rubi into this group. Based on phenotypic analyses, Agrobacterium rubi is atypical but again, is most closely related to biovar 1 isolates (Tighe et al., 2000). The biovar 2 agrobacterial isolates form a second group and, on the basis of $16 \mathrm{~S}$ rRNA sequence analysis, cluster with several members of the genus Rhizobium, including Rhizobium etli, Rhizobium leguminosarum and Rhizobium tropici (Young et al., 2001). The biovar 2 group corresponds to the Agrobacterium rhizogenes group of Holmes \& Roberts (1981). The position of the biovar 3 isolates remains uncertain. Based on biochemical and metabolic characteristics, Ophel \& Kerr (1990) reclassified this group as a new species, Agrobacterium vitis. Most published studies that use $16 \mathrm{~S}$ rRNA sequences place Agrobacterium vitis in or at the periphery of the cluster containing the biovar 1 agrobacteria or in a cluster between the biovar 1 and biovar 2 agrobacteria. On the other hand, $23 \mathrm{~S}$ rRNA sequence analysis places Agrobacterium vitis in its own branch, along with the type strain of Rhizobium galegae (Pulawska et al., 2000). In summary, virtually every inclusive study based on $16 \mathrm{~S}$ rRNA sequence supports the division of the family Rhizobiaceae into at least four clades, one containing the biovar 1 agrobacteria and Agrobacterium rubi, one containing the biovar 2 agrobacteria, Rhizobium leguminosarum and Rhizobium tropici, one containing Sinorhizobium meliloti, and one containing Mesorhizobium loti (for examples, see Sawada et al., 1993; Willems \& Collins, 1993; Yanagi \& Yamasato, 1993; de Lajudie et al., 1994; Wang et al., 1998).

From this summary, it is clear that isolates of Agrobacterium spp. and Rhizobium spp. are related but comprise a large group of diverse bacteria. Since there is such diversity among these groups, there is, in our opinion, insufficient reason to place all of these different species into a single genus, Rhizobium. In this regard we disagree with the statement by Young et al. (2001) that no discriminating characters differentiate species within the genera Agrobacterium and Rhizobium. The biovar 1 agrobacteria exhibit phenotypic traits that clearly differentiate them from members of the genus Rhizobium, as well as from the other agrobacteria. Allen \& Allen (1950) published a table listing as many as 18 traits culled from the literature of the time by which the fast-growing rhizobia and members of the genus Agrobacterium could be differentiated. This conclusion is further supported by more recent studies (Holmes \& Roberts, 1981; de Lajudie et al., 1994), and is nowhere made clearer than in the auxanographic dendograms of de Lajudie et al. (1994). Their phenotypic cluster analysis supports the inclusion of the biovar 1 and 2 agrobacteria, as well as Sinorhizobium meliloti, into a group that is separate from all of the rhizobia examined, clearly a conclusion that is inconsistent with the proposals of Young et al. (2001). Even the data presented by Young et al. (2001) in their Table 1 support the existence of characters that define and differentiate the agrobacteria from the genus Rhizobium. Moreover, even when traits appear to be identical, caution is warranted because the physiology and biochemistry, and therefore the genetic structure underlying these characters, may be different. For example, virtually all members of the family Rhizobiaceae catabolize lactose, making this trait seemingly non-discriminating. However, the biovar 1 agrobacteria catabolize this sugar and certain other disaccharides such as sucrose by a pathway quite different from that used by other members of the family (Bernaerts \& DeLey, 1963). If we were to apply the criteria used by Young et al. (2001) to the genera Rhizobium and Sinorhizobium, then the phenotypic data of de Lajudie et al. (1994) provides no support for separating these two genera. In fact, we note with some puzzlement that while Young et al. (2001) dismiss the absence of such phenotypic support for the division of Rhizobium and Sinorhizobium, claiming that 'pending' information supports the separation, they place defining weight on a minimalistic and itself incomplete set of phenotypic traits as shown in their Table 1 to combine the agrobacteria with the rhizobia. Nevertheless, even the comparisons shown in their Table 1 clearly define the biovar 1 agrobacteria in comparison with the rhizobia.

Young et al. (2001) use the lack of congruence between results from several types of analyses (DNA hybridization patterns, biochemical traits, fatty acid profiles) as evidence that the genus Agrobacterium has no legitimacy. Beyond the fact that these analyses do indeed provide defining features, this argument is itself specious. The problem of congruence, or lack thereof, between datasets is not specific to the Rhizobium/Agrobacterium cluster. Rather, lack of congruence can be inherent to the data type and to the algorithms used to analyse the data. Inconsistencies among datasets also may reflect a lack of informative characters among results of different approaches (Moreira \& Philippe, 2000). Incongruities also can reflect the degree to which two organisms have acquired horizontally transferred DNA from different sources (Brochier et al., 2000) and therefore be poor measures of speciation. Given these difficulties, more weight should be accorded to similarities than to dissimilarities when grouping organisms into phylogenetic relationships. By this criterion of similarities, there exist sets of like traits among members of the genus Rhizobium and other sets of like traits among members of the genus Agrobacterium, and the two groups do not share these sets in common.

Young et al. (2001) claim that the high relatedness of $16 \mathrm{~S}$ rRNA sequences, less than $7 \%$ mismatch, warrants regrouping the agrobacteria and the rhizobia into the single genus Rhizobium. However, the authors note that such a comparison cannot be used as the sole criterion, otherwise members of the genera Brucella and Bartonella must be transferred into the genus Rhizobium since the three share $16 \mathrm{~S}$ rRNA sequences that differ by less than $7 \%$. A consistent application of this criterion would also void the separation of the genus Sinorhizobium from the other rhizobia, since the $16 \mathrm{~S}$ rRNA sequences of these organisms are more than $97 \%$ identical. The reasoning used by Young et al. (2001) also conflicts with the recognition of Salmonella 
and Escherichia as separate genera even though the $16 \mathrm{~S}$ rRNA sequences among species of these genera share more than $95 \%$ identity. These examples illustrate the point that $16 \mathrm{~S}$ rRNA sequence homologies cannot be used as the predominant criterion for the separation or consolidation of different groups at the genus level. Although Young et al. (2001) make this point, they chose to ignore it in the case of Agrobacterium and Rhizobium by placing considerable and undue weight on comparative $16 \mathrm{~S}$ rRNA sequence analysis, which in our opinion is the only new data they bring to their paper. From these points, namely the phenotypic diversity of the family coupled with the inappropriate reliance placed on $16 \mathrm{~S}$ rRNA homologies, we argue that Young et al. (2001) have failed to make a compelling case for combining species of Agrobacterium and Rhizobium into a single genus.

We believe that there are valid and compelling scientific reasons to retain Agrobacterium and Rhizobium as separate genera. First, as detailed above, the agrobacteria exhibit phenotypic characteristics that clearly set them apart from other members of the family Rhizobiaceae. Second, the genome structure of certain members of the genus Agrobacterium differs profoundly from that of other members of the family. Most notably, the chromosomal complement of the biovar 1 agrobacteria and of at least one isolate of Agrobacterium rubi is composed of two chromosomes, one circular and one linear (Jumas-Bilak et al., 1998). This organization is quite different from that of the other members of the family Rhizobiaceae, which contain one or two circular chromosomes, depending upon the species and isolate (Jumas-Bilak et al., 1998). Third, although no complete genome sequence is available for any member of the genus Rhizobium, the genome of the biovar 1 Agrobacterium tumefaciens strain C58 (Goodner et al., 2001; Wood et al., 2001) is now completely known at the nucleotide sequence level. We predict that while there may indeed be large regions of similarity between the circular chromosome of biovar 1 agrobacteria and one of the circular elements of Rhizobium leguminosarum, the linear chromosome of the biovar 1 agrobacteria will differ significantly in its coding capacity from the other large circular elements found in most species of Rhizobium. This point will be resolved only after comparative analysis of the complete genome sequences of selected members of the genera Agrobacterium and Rhizobium. However, what is certain is that these differences in gene complements will express themselves as differences in phenotypes, that is, taxonomically differentiatable traits, if only one knew the traits to examine. Fourth, the chromosomes of Rhizobium spp. and also of Sinorhizobium meliloti contain characteristic nucleotide repeat elements called RIMEs (rhizobium-specific intergenic mosaic elements), which are not present in the genome of the biovar 1 Agrobacterium tumefaciens strain C58 (Østerås et al., 1995). Nor does there seem to exist an Agrobacterium-specific RIME-type element in the genome of strain C58. These elements may well be involved in genome rearrangements and evolution, and their absence from the genomes of biovar 1 agrobacteria is striking in its contrast to the rhizobia. Thus, the phenotypic and genotypic evidence indicate that the biovar 1 agrobacteria are significantly different from other members of the family Rhizobiaceae. Fifth, an analysis of current available data suggests that the characteristics of the plant-microbe interaction should not be ignored when evaluating differences among species of Agrobacterium and Rhizobium. For example, transconjugants of biovar 1 Agrobacterium strains carrying sym plasmids from several biovars of Rhizobium leguminosarum produced morphologically atypical nodules that failed to fix nitrogen (Hooykaas et al., 1981, 1982). Similar atypical reactions were observed in plants infected with Agrobacterium harbouring a sym plasmid from Sinorhizobium meliloti (Truchet et al., 1984). Nor do the rhizobia necessarily become tumorigenic upon acquisition of a Ti plasmid. Sinorhizobium meliloti, into which a Ti plasmid from Agrobacterium tumefaciens had been introduced, failed to induce tumours on any plant species tested (Van Veen et al., 1989). From these observations it seems likely that Agrobacterium and Rhizobium carry on their chromosomes genus-specific gene sets that characterize the nature of their interactions with plants, irrespective of the determinants carried on sym or Ti plasmids. In our opinion, the agrobacteria and the rhizobia are diverging along their own evolutionary paths and these paths are tied, in part, to the specific characters of their interactions with host plants.

As noted by Young et al. (2001), there clearly exist problems in the taxonomies of the genera Agrobacterium and Rhizobium. However, these difficulties cannot be resolved simply by renaming the agrobacteria. We propose that the genus Agrobacterium as described by Kersters \& De Ley (1984) be retained for the present, and that this genus descriptor be used certainly for the biovar 1 isolates, and also for species Agrobacterium rubi. As noted above, there is no compelling reason to include these bacteria in the genus Rhizobium, and genome structure as well as classical taxonomic measures support their division into a separate genus.

The issue is less clear with respect to the biovar 2 agrobacteria; these isolates appear to be more closely related overall to members of the genus Rhizobium than they are to the biovar 1 agrobacteria. Nevertheless, we propose to retain provisionally the biovar 2 agrobacteria within the genus Agrobacterium, as described above, for two reasons. First, given the polyphyletic nature of the family, there is no pressing need to redefine the genus status of the biovar 2 agrobacteria. This issue can be more thoroughly and definitively addressed when complete genome sequences are available for representative members of the relevant groups. Second, there is the issue of how we presently define these organisms as agrobacteria or rhizobia; namely a combination of phenotypic and genetic traits in conjunction with their interactions with host plants. Leaving aside the problems of plasmids and the traits they confer, it is quite possible that biovar 2 agrobacteria, in their pathogenic and 
non-pathogenic forms, represent a group that is diverging from that which has evolved as plant symbionts, the rhizobia. Consistent with this interpretation, biovar 2 agrobacteria into which sym plasmids have been introduced induce atypical nodules (Paul Hooykaas, personal communication). Moreover, not all non-nodulating isolates classified within the genus Rhizobium gain the ability to nodulate host plants upon acquisition of a sym plasmid (Jarvis et al., 1989). Such isolates may represent bacteria that have evolved along the agrobacterial lineage, i.e. the biovar 2 agrobacteria. One could conclude from these two observations that the biovar 2 agrobacteria do differ from the fast-growing rhizobia.

Clearly, more studies are required to resolve these issues, and until such definitive studies are available, we propose retention of the taxonomic status quo. It is clear from several published analyses of the rhizobia, including isolates unable to nodulate host plants, that these bacteria can be differentiated easily from the biovar 1 agrobacteria (Jarvis et al., 1989; Soberón-Chávez \& Nájera, 1989; Segovia et al., 1991). The opposite is also true; isolates of agrobacteria, even those of biovar 2, can be differentiated from the rhizobia using selective media and standard keys (for example, see Schroth et al., 1965; Du Plessis et al., 1984; López et al., 1988; Bouzar et al., 1993, 1995).

With respect to species designations, we remain in a quandary. Young et al. (2001) contend that the epithets tumefaciens and rhizogenes are formally untenable because they describe traits that have as their genetic bases transmissible plasmids. But perhaps we should remember one purpose of taxonomy and that is to provide stable, meaningful names by which to refer to an organism in comparison with and in contrast to other organisms. The names should be designed for easy recognition and recollection. And if we are to do away with tumefaciens (tumour-inducing) as proposed by Young et al. (2001), why retain rhizogenes (root-inducing), also as proposed by Young et al. (2001)? Both species names describe a pathology, and to make matters worse, a variable trait conferred by a transmissible plasmid. In our opinion, retention of one but not the other cannot be excused on the basis of established rules for assigning species names. Moreover, we contend that these species names may in fact be tenable. It is becoming evident that the genomes of the agrobacteria, and perhaps also those of Rhizobium, Sinorhizobium and Mesorhizobium are evolving in concert with their plasmids and their host plants (see for example: Jarvis et al., 1989; Soberón-Chávez \& Nájera, 1989; Segovia et al., 1991; Bouzar et al., 1993; Otten et al., 1996; Pionnat et al., 1999; Ridé et al., 2000). While it is true that the large defining plasmids of one group can, on occasion, confer their specific phenotype on a non-cognate chromosomal background, the opposite also may be the case; there often is a required specificity, usually in the quantitative sense, between the bacterium, its plasmids and its host plants.

The goal in taxonomy is to identify the dividing lines in the continuum of bacterial genotypes that meaningfully describe and delineate genera. In our opinion the polyphasic differences between the rhizobia and the agrobacteria, which include chromosomal structure, presence or absence of RIMEs, auxanographic differences, differences in fatty acid profiles, and even divergences in $16 \mathrm{~S}$ rRNA sequences set the two groups of bacteria apart at the genus level. These sets of criteria in themselves constitute reason for caution, and caution, which equates to stability, in our opinion dictates retention of the genus Agrobacterium. Consistent with our proposal, from their detailed study of the family Rhizobiaceae, de Lajudie et al. (1994) conclude that, although in need of revision at the species level, the genus Agrobacterium should be retained. Moreover, the microbial physiologists, geneticists and molecular biologists, as well as the plant scientists who work with Agrobacterium spp. know and use these organisms by their classical genus name. We believe that, in the absence of compelling and meaningful taxonomic weight, there is little to be gained by changing this terminology. Certainly, the scientific arguments to do so are not compelling. On the other hand, given the wide use of Agrobacterium species in disciplines ranging from basic bacteriology, genetics and molecular biology, through microbial physiology and enzymology, to plant molecular biology and biotechnology, there is the certainty of much confusion attendant to the unnecessary and unwarranted changes in taxonomic nomenclature proposed by Young et al. (2001).

This paper is co-signed by the following individuals, all of whom have communicated to the Editor of IJSEM their agreement with the positions of the authors concerning the taxonomic validity of the genus Agrobacterium. Some of the co-signatories have contributed to the Editor additional information in support of the position of the authors.

Drs Fredrick M. Ausubel, Department of Genetics, Harvard Medical School, Boston, MA, USA; Jacques Balandreau, Université Claude Bernard, Lyon, France; Rene Bally, Université Claude Bernard, Lyon, France; Lois Banta, Department of Biological Sciences, Williams College, Williamstown, MA, USA; Andrew Binns, Department of Biology, University of Pennsylvania, Philadelphia, PA, USA; Peter Bottomley, Department of Microbiology, Oregon State University, Corvallis, OR, USA; Hacène Bouzar, Sakata Seed America, Inc., Salinas, CA, USA; Susana Brom, Centro de Investigación sobre Fijación Nitrógeno, Cuernevaca, Mexico; William J. Broughton, Laboratoire de Biologie Moléculaire des Plantes Superieures, Université Genéve, Switzerland; Thomas J. Burr, Department of Plant Pathology, Cornell University, Geneva, NY, USA; Miguel A. Cevallos, Centro de Investigación sobre Fijación Nitrógeno, Cuernavaca Mexico; Jai-Soo Cha, Chung Buk National University, Chongju, Korea; Mary-Dell Chilton, Syngenta, Research Triangle Park, NC, USA; William Scott Chilton, Department of Botany, North Carolina State University, Raleigh, NC, USA; Peter Christie, Department of Microbiology and Molecular Genetics, University of Texas, Houston Medical School, Houston, TX, USA; 
Thomas Clemente, Department of Agronomy, University of Nebraska, Lincoln, NE, USA; Paolo Costantino, Departmento di Genetica e Biologia Molecolare, Universita di Roma, Roma, Italy; Anath Das (and two members of his group), Department of Biochemistry, Molecular Biology and Biophysics, University of Minnesota, St Paul, MN, USA; Christine Desfeux-Oger, UMR-CNRS, Ecologie Microbienne, Université Claude Bernard, Lyon, France; Yves Dessaux, Institut des Sciences Végétales, CNRS, Gif-sur-Yvette, France; Allan Downie (and eight members of his group), The John Innes Centre, Norwich, UK; Turlough Finan, Department of Biology, McMaster University, Hamilton, Ontario, Canada; W. Clay Fuqua, Department of Biology, Indiana University, Bloomington, IN, USA; Stanton B. Gelvin, Department of Biological Sciences, Purdue University, West Lafayette, IN, USA; Lourdes Girard, Centro de Investigación sobre Fijación Nitrógeno, Cuernavaca, Mexico; Bradley Goodner, Department of Biology, Hiram College, Hiram, $\mathrm{OH}$, USA; Champa Gopalan, Department of Agronomy and Horticulture, New Mexico State University, Las Cruces, NM, USA; Milton P. Gordon, Department of Biochemistry, University of Washington, Seattle, WA, USA; Barbara Hohn, Friedrich Mischer Institute, Basel, Switzerland; Marcelle Holsters, Laboratorium Genetika, Universiteit Gent, Gent, Belgium; Paul J. J. Hooykaas, Institute of Molecular Plant Sciences, University of Leiden, Leiden, The Netherlands; Michael F. Hynes, Department of Biological Sciences, University of Calgary, Calgary, Alberta, Canada; Ingyu Hwang, Department of Plant Pathology, Seoul National University, Suwon, Korea; Shouguang Jin, Department of Molecular Genetics and Microbiology, University of Florida, Gainesville, FL, USA; Jeffrey B. Jones, Department of Plant Pathology, University of Florida, Gainesville, FL, USA; Clarence I. Kado, Department of Plant Pathology, University of California, Davis, CA, USA; Michael L. Kahn, Department of Microbiology and Molecular Biosciences, Washington State University, Pullman, WA, USA; Heidi B. Kaplan, Department of Microbiology and Molecular Genetics, University of Texas, Houston Medical School, Houston, TX, USA; John Kemp, Department of Entomology, Plant Pathology and Weed Sciences, New Mexico State University, Las Cruces, NM, USA; Kun-Soo Kim, Department of Life Sciences, Sogang University, Seoul, Korea; Theresa Koehler, Department of Microbiology and Molecular Genetics, University of Texas, Houston Medical School, Houston, TX, USA; Adam Kondorosi, Institut des Sciences Végétales, CNRS, Gifsur-Yvette, France; Philippe de Lajudie, Laboratoire des Symbioses Tropicales et Méditerranéennes, Montpellier, France; Maria M. López, Instituto Valenciano de Investigaciones Agrarias, Moncada, Valencia, Spain; David Lynn (and 12 members of his group), Departments of Chemistry and Biology, Emory University, Atlanta, GA, USA; William Margolin, Department of Microbiology and Molecular Genetics, University of Texas, Houston Medical School, Houston, TX, USA; Eustuquio MartinezMolina, Departmento Microbíolgia y Genética, Campus
M. Unamuno, Salamanca, Spain; Pedro F. Mateos Gonzalés, Departmento Microbíologia y Genética, Campus M. Unamuno, Salamanca, Spain; Ann G. Matthysse, Department of Biology, University of North Carolina, Chapel Hill, NC, USA; Patrick Mavinguy, Ecologie Microbienne, Université Claude Bernard, Lyon, France; Eric Messens, Department of Molecular Genetics, Universiteit Gent, Gent, Belgium; Yvan Moënne-Loccoz, Université Claude Bernard, Lyon, France; Sharon Long, Gilbert Laboratory, Stanford University, Stanford, CA, USA; Xavier Nesme, Ecologie Microbienne, Université Claude Bernard, Lyon, France; Eugene W. Nester, Department of Microbiology, University of Washington, Seattle, WA, USA; Marc Neyra, Laboratoire de Microbiologie, IRD - Dakur, Dakur, Sengal; Philippe Normand, Microbial Ecology, Université Claude Bernard, Lyon, France; Léon Otten, Department of Cell Division and Plant Development, Université Louis Pasteur, Strasbourg, France; L. Nicholas Ornston, Department of Molecular, Cellular and Developmental Biology, Yale University, New Haven, CT, USA; Karrupiah Palanichelvam, Plant Science Unit, University of Missouri, Columbia, MO, USA; Shen Q. Pan, Department of Biological Sciences, National University of Singapore, Singapore; Donna Parke, Department of Molecular, Cellular and Developmental Biology, Yale University, New Haven, CT, USA; Ramón Penyalver, Instituto Valenciano de Investigaciones Agrarias, Moncada-Valencia, Spain; Xavier Perret, Laboratoire de Biologie Moléculaire des Plantes Superieures, Université Genéve, Switzerland; Annik Petit, Institut des Sciences Végétales, CNRS, Gif-sur-Yvette, France; Steven G. Pueppke, Agricultural Experiment Station, University of Illinois at Urbana-Champaign, Urbana, IL, USA; David Romero, Centro de Investigación sobre Fijación Nitrógeno, Cuernevaca Moreles, Mexico; Michael J. Sadowsky, Department of Soil, Water and Climate, University of Minnesota, St Paul, MN, USA; Pascal Simonet, Group on Gene Transfer Among Bacteria, Université Claude Bernard, Lyon, France; Herman Spaink, Instituut Moleculaire Plantkunde, Rijks Universiteit Leiden, Leiden, The Netherlands; Todd R. Steck, Department of Biology, University of North Carolina - Charlotte, Charlotte, NC, USA; Gary Stacey, Department of Plant Microbiology and Pathology, University of Missouri, Columbia, MO, USA; Sandor Süle, Plant Protection Institute, Hungarian Academy of Sciences, Budapest, Hungary; Laurent Sutra, UMR de Pathologie Végétale, INRA, Beaucouzé, France; Nobukazu Tanaka, Center for Gene Science, Hiroshima University, Hiroshima, Japan; David Tepfer, Laboratoire de Biologie de la Rhizosphére, INRA, Versailles, France; Encarna Velázquez Perez, Departmento Microbíologia y Genética Campus M. Unamuno, Salamanca, Spain; Graham C. Walker, Department of Biology, Massachusetts Institute of Technology, Cambridge, MA, USA; Stephen C. Winans, Department of Microbiology, Cornell University, Ithaca, NY, USA; Derek Wood, Department of Microbiology, University of Washington, Seattle, WA, USA; Shaw-Jyre $\mathrm{Wu}$, Central National University, Chung Li, Taiwan, 
Republic of China; Patricia Zambryski (and three members of her group), Department of Plant and Microbial Biology, University of California, Berkeley, CA, USA; Jin Zhang, Department of Pharmacology, University of California, San Diego, CA, USA.

\section{Acknowledgements}

We thank Xavier Nesme for his comments and discussion as well as input from all of our colleagues. Work in the laboratory of S. K. F. is supported by grant R01 GM52465 from the NIH and C-FAR grant IDACF01I-3-3 CS from the State of Illinois. Work in the laboratory of PO is supported by grant ACI Jeune Chercheur 22-2002-140 from the Minèstere de la Recherche.

\section{Note Added in Proof}

Two recent publications (Weller et al., 2002; Van Berkum et al., 2003) present results from the phylogenetic analysis of nucleotide sequences that are consistent with our position that there is no sound scientific evidence that warrants combining the members of the genus Agrobacterium into the genus Rhizobium.

\section{References}

Allen, E. K. \& Allen, O. N. (1950). Biochemical and symbiotic properties of the rhizobia. Bacteriol Rev 14, 273-330.

Bernaerts, M. J. \& DeLey, J. (1963). A biochemical test for crown gall bacteria. Nature 197, 406-407.

Bouzar, H., Quadah, D., Krimi, Z., Jones, J. B., Trovato, M., Petit, A. \& Dessaux, Y. (1993). Correlative association between resident plasmids and the host chromosome in a diverse Agrobacterium soil population. Appl Environ Microbiol 59, 1310-1317.

Bouzar, H., Chilton, W. S., Nesme, X., Dessaux, Y., Vaudequin, V., Petit, A., Jones, J. B. \& Hodge, N. C. (1995). A new Agrobacterium strain isolated from aerial tumors on Ficus benjamina L. Appl Environ Microbiol 61, 65-73.

Brochier, C., Philippe, H. \& Moreira, D. (2000). The evolutionary history of ribosomal protein RpS14: horizontal gene transfer at the heart of the ribosome. Trends Genet 16, 529-533.

de Lajudie, P., Willems, A., Pot, B., Dewettinck, D., Maestrojuan, G., Neyra, M., Collins, M. D., Dreyfus, B., Kersters, K. \& Gillis, M. (1994). Polyphasic taxonomy of rhizobia: emendation of the genus Sinorhizobium and description of Sinorhizobium meliloti comb. nov., Sinorhizobium saheli sp. nov., and Sinorhizobium teranga sp. nov. Int J Syst Bacteriol 44, 715-733.

Du Plessis, H. J., Van Vuuren, H. J. J. \& Hatting, M. J. (1984). Biotypes and phenotypic groups of strains of Agrobacterium in South Africa. Phytopathology 74, 524-529.

Galibert, F., Finan, T. M., Long, S. R. \& 53 other authors (2001). The composite genome of the legume symbiont Sinorhizobium meliloti. Science 293, 668-672.

Goodner, B., Hinkle, G., Gattung, S. \& 28 other authors (2001). Genome sequence of the plant pathogen and biotechnology agent Agrobacterium tumefaciens C58. Science 294, 2323-2328.

Holmes, B. \& Roberts, P. (1981). The classification, identification and nomenclature of Agrobacteria. J Appl Bacteriol 50, 443-467.

Hooykaas, P. J. J., van Brussel, A. A. N., den Dulk-Ras, H., van Slogteren, G. M. S. \& Schilperoort, R. A. (1981). Sym plasmid of $R$. trifolii expressed in different rhizobial species and in Agrobacterium tumefaciens. Nature 276, 634-636.
Hooykaas, P. J. J., Snijdewint, G. M. \& Schilperoort, R. A. (1982). Identification of the Sym plasmid of Rhizobium leguminosarum strain 1001 and its transfer to and expression in other rhizobia and Agrobacterium tumefaciens. Plasmid 8, 73-82.

Jarvis, B. D. W., Ward, L. J. H. \& Slade, E. A. (1989). Expression by soil bacteria of nodulation genes from Rhizobium leguminosarum biovar trifolii. Appl Environ Microbiol 55, 1426-1434.

Jordan, D. C. (1984). Genus I. Rhizobium Frank 1889, 338 ${ }^{\mathrm{AL}}$. In Bergey's Manual of Systematic Bacteriology, vol. 1, pp. 235-242. Edited by N. R. Krieg \& J. G. Holt. Baltimore: Williams \& Wilkins.

Jumas-Bilak, E., Michaux-Charachon, S., Bourg, G., Ramuz, M. \& Allardet-Servent, A. (1998). Unconventional genomic organization in the alpha subgroup of the Proteobacteria. J Bacteriol 180, 2749-2755.

Keane, P. J., Kerr, A. \& New, P. B. (1970). Crown gall of stone fruit. II. Identification and nomenclature of Agrobacterium isolates. Aust J Biol Sci 23, 585-595.

Kerr, A. \& Panagopoulos, C. G. (1977). Biotypes of Agrobacterium radiobacter var. tumefaciens and their biological control. Phytopathol $Z$ 90, 172-179.

Kersters, K. \& De Ley, L. (1984). Genus III. Agrobacterium Conn 1942, 359 ${ }^{\mathrm{AL}}$. In Bergey's Manual of Systematic Bacteriology, vol. 1, pp. 244-254. Edited by N. R. Krieg \& J. G. Holt. Baltimore: Williams \& Wilkins.

López, M. M., Gorris, M. T. \& Montojo, A. M. (1988). Opine utilization by Spanish isolates of Agrobacterium tumefaciens. Plant Pathol 37, 565-572.

Moreira, D. \& Philippe, H. (2000). Molecular phylogeny: pitfalls and progress. Int Microbiol 3, 9-16.

Ophel, K. \& Kerr, A. (1990). Agrobacterium vitis sp. nov. for strains of Agrobacterium biovar 3 from grapevines. Int J Syst Bacteriol 40, 236-241.

Østerås, M., Stanley, J. \& Finan, T. M. (1995). Identification of rhizobium-specific intergenic mosaic elements within an essential two-component regulatory system in Rhizobium species. J Bacteriol 177, 5485-5494.

Otten, L., De Ruffray, P., Momol, E. A., Momol, M. T. \& Burr, T. (1996). Phylogenetic relationships between Agrobacterium vitis isolates and their Ti plasmids. Mol Plant-Microbe Interact 9, 782-786.

Pionnat, S., Keller, H., Héricher, D., Bettachini, A., Dessaux, Y., Nesme, X. \& Poncet, C. (1999). Ti plasmids from Agrobacterium characterize rootstock clones that initiated a spread of crown gall disease in Mediterranean countries. Appl Environ Microbiol 65, 4197-4206.

Pulawska, J., Maes, M., Willems, A. \& Sobiczewski, P. (2000). Phylogenetic analysis of 23S rRNA gene sequences of Agrobacterium, Rhizobium and Sinorhizobium strains. Syst Appl Microbiol 23, 238-244.

Ridé, M., Ridé, S., Petit, A., Bollet, C., Dessaux, Y. \& Gardan, L. (2000). Characterization of plasmid-borne and chromosomeencoded traits of Agrobacterium biovar 1, 2, and 3 strains from France. Appl Environ Microbiol 66, 1818-1825.

Sawada, H., leki, H., Oyaizu, H. \& Matsumoto, S. (1993). Proposal for rejection of Agrobacterium tumefaciens and revised descriptions for the genus Agrobacterium and for Agrobacterium radiobacter and Agrobacterium rhizogenes. Int J Syst Bacteriol 43, 694-702.

Schroth, M. N., Thompson, J. P. \& Hildebrand, D. C. (1965). Isolation of Agrobacterium tumefaciens - A. radiobacter group from soil. Phytopathology 55, 645-647.

Segovia, L., Piñero, D., Palacios, R. \& Martínez-Romero, E. (1991). Genetic structure of a soil population of nonsymbiotic Rhizobium leguminosarum. Appl Environ Microbiol 57, 426-433. 
Soberón-Chávez, G. \& Nájera, R. (1989). Isolation from soil of Rhizobium leguminosarum lacking symbiotic information. Can J Microbiol 35, 464-468.

Tighe, S. W., de Lajudie, P., Dipietro, K., Lindström, K., Nick, G. \& Jarvis, B. D. W. (2000). Analysis of cellular fatty acids and phenotypic relationships of Agrobacterium, Bradyrhizobium, Mesorhizobium, Rhizobium and Sinorhizobium species using the Sherlock Microbial Identification System. Int J Syst Evol Microbiol 50, 787-801.

Truchet, G., Rosenberg, C., Vasse, J., Julliot, J.-S., Camut, S. \& Denarie, J. (1984). Transfer of Rhizobium meliloti pSym genes into Agrobacterium tumefaciens: host-specific nodulation by atypical infection. J Bacteriol 157, 134-142.

Van Berkum, P., Terefework, Z., Paulin, L., Soumalainen, S., Lindstrom, K. \& Eardly, B. D. (2003). Discordant phylogenies within the rrn loci of Rhizobia. J Bacteriol 185, 2988-2998.

Van Veen, R. J. M., den Dulk-Ras, H., Schilperoort, R. A. \& Hooykaas, P. J. J. (1989). Ti plasmid containing Rhizobium meliloti are non-tumorigenic on plants, despite proper virulence gene induction and T-strand formation. Arch Microbiol 153, 85-98.

Wang, E. T., van Berkum, P., Beyene, D., Sui, X. H., Dorado, O., Chen, W. X. \& Martínez-Romero, E. (1998). Rhizobium huautlense sp. nov., a symbiont of Sesbania herbacea that has a close phylogenetic relationship with Rhizobium galegae. Int $J$ Syst Bacteriol 48, 687-699.

Weller, S. A., Simpkins, S. A., Stead, D. E., Kurdziel, A., Hird, H. \& Weeks, R. J. (2002). Identification of Agrobacterium spp. present within Brassica napus seed by TaqMan PCR - implications for GM screening procedures. Arch Microbiol 178, 338-343.

Willems, M. \& Collins, M. D. (1993). Phylogenetic analysis of rhizobia and agrobacteria based on $16 \mathrm{~S}$ rRNA gene sequences. Int $J$ Syst Bacteriol 43, 305-313.

Wood, D. W., Setubal, J. C., Kaul, R. \& 48 other authors (2001). The genome of the natural genetic engineer Agrobacterium tumefaciens C58. Science 294, 2317-2323.

Yanagi, M. \& Yamasato, K. (1993). Phylogenetic analysis of the family Rhizobiaceae and related bacteria by sequencing of $16 \mathrm{~S}$ rRNA gene using PCR and DNA sequencer. FEMS Microbiol Lett 107, 115-120.

Young, J. M., Kuykendall, L. D., Martínez-Romero, E., Kerr, A. \& Sawada, H. (2001). A revision of Rhizobium Frank 1889, with an emended description of the genus, and the inclusion of all species of Agrobacterium Conn 1942 and Allorhizobium undicola de Lajudie et al. 1998 as new combinations: Rhizobium radiobacter, $R$. rhizogenes, R. rubi, R. undicola, and R. vitis. Int J Syst Evol Microbiol 51, 89-103. 